\title{
Digital pictures to enhance storytelling amongst special needs children
}

\begin{abstract}
English has a difficult role to play since it is the second language for most Malaysian and in the Malaysian Education system for the special needs as there is no special syllabus for the autistic children. Children with autism are expected to learn the same thing with the rest of the children in the normal school. Autistic children have difficulty to concentrate and therefore the same learning syllabus with the normal children will make them difficult in acquiring the language in a short time. Even though, the normal children will have the difficulty of learning the language but they have a lot of time to learn at home or with their friends around them. In other way, the autistic children will have to learn more than the normal children. Autism is a complex developmental disorder that appears in the first 3 years of life, though it is some times diagnosed much later. It affects the brain's normal development of social and communication skills. Autism is a spectrum that encompasses a wide continuum of behavior (Bailey, D. B., Jr., D. D. Hatton, et al., 2001). Core features include impaired social interactions, impaired verbal and nonverbal communication and restricted and repetitive patterns of behavior. This paper focuses on Asperger syndrome which is also considered as autistic spectrum. This paper investigates Asperger children's motivation level when using digital pictures in creating a short story in the task based English language classroom and investigate the language use in the short story created by asperger children when using digital camera in the task based English language classroom. It is hoped that digital pictures able to enhance storytelling amongst the special needs children.
\end{abstract}

Keyword: Asperger syndrome, autistic children, digital pictures, storytelling 